\title{
DEVELOPMENT AND IMPLEMENTATION OF A REAL-TIME SEDIMENT DISASTER ALERT SYSTEM
}

\author{
TAKEYASU SUZUKI ${ }^{1}$, TAKUMI ITO ${ }^{2} \&$ SATOSHI GOTO ${ }^{1}$ \\ ${ }^{1}$ Disaster and Environmentally Sustainable Administration Research Center, University of Yamanashi, Japan \\ ${ }^{2}$ Civil and Environmental Engineering Course, Integrated Graduate School of Medicine, \\ Engineering, and Agricultural Sciences, University of Yamanashi, Japan
}

\begin{abstract}
For flooding, visual information of rising water levels can signal the timing of residents' evacuation. For impending sediment disasters, however, the state of the groundwater level or soil moisture content in a slope's soil layer cannot be visually confirmed. Therefore, the authors developed a sediment disaster alert system, in part using a color-coded chart that signals evacuation urgency - an "evacuation switch". The system uses a slope's real-time rainfall observation as input data and performs real-time stability analysis based on rainwater runoff and infiltration simulations. In Nishikatsura Town, Yamanashi Prefecture, Japan, a slope designated as a mountain stream from which debris flow is likely to occur was selected as the target. The simulation model was constructed based on results of soil exploration and soil testing. The website for a sediment disaster alert system was developed by combining the rainfall observation system and the simulation. To provide the evacuation switch for residents, this website expresses risk of sediment disasters not by a safety factor but by a chart showing the current groundwater level with respect to the groundwater level at which the slope becomes unstable and collapses.
\end{abstract}

Keywords: sediment disaster, real-time rainfall observation, simulation, sediment disaster alert system, switch for evacuation.

\section{INTRODUCTION}

Abnormal weather caused by global warming has brought about unprecedented torrential rain, causing rain-related disasters in various parts of Japan. The 2017 Northern Kyushu heavy-rain disaster caused 42 casualties (40 dead and two missing), and the 2018 Western Japan heavy-rain resulted in 232 casualties (224 dead and eight missing). In 2019, Typhoon No. 19 killed 104, and in July 2020, a heavy-rain disaster killed 84. Many of these casualties were victims of sediment disasters, which, among heavy-rain-related disasters, are most likely to be fatal.

The most effective means of protecting lives against sediment disasters is early evacuation, and for early evacuation, municipalities have to anticipate sediment disasters, issue evacuation information, and establish a reliable evacuation system. In Japan, in line with the 2001 Sediment Disaster Prevention Act, municipalities issue evacuation information based on sediment disaster warnings announced by prefectures and the Japan Meteorological Agency. For short-duration heavy rainfall, however, sediment disaster warning information might not be announced in a timely fashion. But even if the information is announced, a sediment disaster often occurs before the announcement. And unfortunately, residents might not evacuate even if evacuation information is issued.

Indeed, evacuation due to a sediment disaster warning involves several issues. First, information is based on the critical line of a two-dimensional plot - with the soil-water index on the horizontal axis and 60 minutes' accumulated rainfall on the vertical axis. When, on this two-dimensional plane, a moving point is judged to have exceeded the critical line (after 2 hours), sediment disaster alert information is issued. 
The soil water index, calculated with 60 minutes' accumulated rainfall as input, is the most important parameter for sediment disaster warning information [1]. Sixty minutes' accumulated rainfall is analysed by the Automated Meteorological Data Acquisition System precipitation radar and corrected by rainfall observation results on the ground. Although the Japan Meteorological Agency announces the amount of precipitation at a resolution of $1 \mathrm{~km}$, the accuracy of rainfall observation points on the ground is only $\sim 10 \mathrm{~km}$. Thus, it is unsuitable for local rainfall estimation.

Therefore, we placed real-time weather sensors in sediment disaster hazard areas and, to issue evacuation information, predicted disasters based on local observational rainfall data. Furthermore, we demonstrated the possibility of forecasting rainfall and sediment disaster by evaluating auto-correlation and cross-correlation of rainfall intensity between rainfall observation stations in real-time. In adjacent municipalities' sediment disaster hazard areas, when rainfall observation is conducted at specific points in real-time, rainfall of $\sim 1$ hour can be forecast using cross-correlation between observation points, regardless of municipal boundaries [1].

This paper reports a new simulation method for evaluating risk of sediment disasters in real-time by combining rainwater infiltration into the soil, groundwater level generation and rise, and unsaturated surface slope stability by inputting real-time rainfall observation data. Additionally, this simulation is incorporated into a website providing a signal to evacuate, or an "evacuation switch", for community residents [2].

\section{PREDICTION OF SEDIMENT DISASTERS BASED ON SLOPE STABILITY ANALYSIS}

To improve the accuracy of predicting sediment disasters, improving the accuracy of predicting heavy rainfall and of local slopes' stability is important. Since slopes' inclination angle, surface thickness, and physical properties, including strength constants and infiltration characteristics of the soil's surface layer, differ, their stability differs depending on location even under the same rainfall conditions.

Many methods have been proposed to estimate beginning landslides and debris flows due to heavy-rain via stable analysis of a soil mass on a slope's base rock. Sliding resistance of a soil mass can be expressed by Mohr-Coulomb's theory of shear strength with parameters of cohesion, normal stress, and internal friction angle. On the other hand, sliding external force is a downward component of the weight of the soil mass on base rock. That is, if $F_{s}$ expressed by eqn (1), which is the ratio of slip resistance to slip external force, is greater than 1 , the soil mass is stable; if less than 1, the soil mass is unstable; and at exactly 1, the ratio is balanced, and the soil mass is expected to slide.

$$
F_{s}=\frac{\tau_{g}}{\tau_{r}}
$$

As a result of rainwater infiltration, when a groundwater layer forms on the surface layer covering the slope's base rock, the weight of the soil mass increases, and the numerator of $F_{S}$ formula increases. On the other hand, since effective stress decreases due to buoyancy, the denominator corresponding to shear resistance decreases, and consequently, it can be expected that when the $F_{s}$ falls below 1, the surface layer starts to slide. Here three methods are used for handling rainwater infiltration into the surface layer. The first is a method in which all rainwater permeates; in the second, only part of rainwater determined by the runoff coefficient permeates; and, in the third, an inflow amount is calculated by runoff analysis.

To calculate $F_{S}$ accurately, evaluation of vertical force by saturation of unsaturated ground formed by rainwater infiltration is necessary. Determining conditions under which the 
groundwater level begins to form is also necessary. When some heavy-rain permeates from the ground surface to the surface layer and permeates downward in an unsaturated state to reach base rock, saturation begins from the soil layer's lower part, and the groundwater level is formed. Groundwater flows downstream along the slope's surface layer, supplied from upstream and from the ground surface. By analyzing groundwater seepage in this way, the inclination angle $\beta$ of the slope shown in Fig. 1, the groundwater level $h_{w}$, the saturated unit weight $\gamma_{\text {sat }}$ of surface soil below groundwater level, and the wet unit weight $\gamma_{t}$ of surface soil above groundwater level can be obtained. Then, the safety factor $F_{S}$ can be expressed as follows:

$$
F_{S}=\frac{c+\sigma^{\prime} \tan \varphi}{\left(\gamma_{t}\left(H-h_{w}\right)+\gamma_{s a t} \cdot h_{w}\right) \sin \beta},
$$

where, $c$ is the soil's cohesion, $\varphi$ is the soil's internal friction angle and $\sigma^{\prime}$ is an effective stress on base rock and can be expressed by the following equation:

$$
\sigma^{\prime}=\left(\gamma_{t}\left(H-h_{w}\right)+\left(\gamma_{s a t}-\gamma_{w}\right) h_{w}\right) \cos \beta .
$$

Thus, slope stability due to straight sliding on an infinite slope with inclination angle $\beta$ is evaluated by the following safety factor, $F_{S}$ :

$$
F_{S}=\frac{c+\left\{\gamma_{t}\left(H-h_{w}\right)+\left(\gamma_{s a t}-\gamma_{w}\right) h_{w}\right\} \cos \beta \tan \varphi}{\left\{\gamma_{t}\left(H-h_{w}\right)+\gamma_{s a t} h_{w}\right\} \sin \beta},
$$

where, $c$ is cohesion $\left(\mathrm{kN}^{2}\right) ; \gamma_{t}$ is wet unit weight soil $\left(\mathrm{kN}^{3}\right) ; \gamma_{s a t}$ is saturated unit weight of soil $\left(\mathrm{kN}^{3}\right) ; \gamma_{w}$ is unit weight of water $\left(\mathrm{kN}^{3}\right) ; H$ is the surface layer thickness of $(\mathrm{m})$; $\beta$ is the target slope's inclination angle; $\varphi$ is the soil's internal friction angle; and $h_{w}$ is the groundwater level (m).

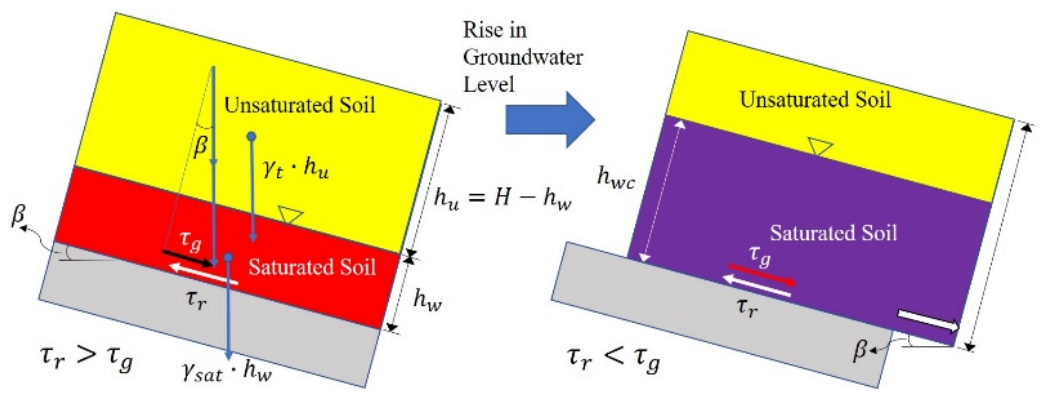

Figure 1: Conceptual diagram of slope stability analysis.

For slopes of constant gradient, Montrasio et al. proposed that groundwater level be a function of time related to precipitation intensity [3]. Kawabata et al. conducted rainfall experiments with rainfall intensities of $5 \mathrm{~mm} /$ hour, $25 \mathrm{~mm} /$ hour, and $50 \mathrm{~mm} /$ hour, finding that a high-water content zone with a degree of saturation corresponding to these rainfall intensities was formed from the ground surface's vicinity [4]. By groundwater seepage analysis, they proposed to determine the process of groundwater level formation when the high-water content zone moves downward, reaches the rock surface, and the groundwater level is formed and rises. Furthermore, to analyze $F_{S}$ in each soil layer cross section when the slope and surface thickness are given, Kawabata et al. proposed a method of analyzing twodimensional groundwater seepage along the slope [4]. 
As described above, for improving the accuracy of slope stability analysis, accurate evaluation of the soil's shear resistance and the soil layer's weight is necessary. To calculate the soil layer's weight accurately, tracking the soil's wet density and groundwater level (saturated soil height), which change according to rainfall intensity, is necessary. On the other hand, these parameters are also necessary for correct evaluation of effective stress in shear resistance.

The method of evaluating occurrence of sediment disasters was proposed from the ratio of the groundwater level to the collapsed groundwater level, in which the safety factor $F_{S}$ reaches 1 , by observing pore water pressure on the local slope and estimating the groundwater level [5]. Furthermore, a system for evaluating a slope's safety factor by estimating the soil's cohesion, the internal friction angle, the soil's weight, and the pore water pressure based on field observation of the soil layer's water content has also been adopted for practical use [6].

\section{CONSTRUCTION OF SEDIMENT DISASTER RISK ANALYSIS AND VISUAL REPRESENTATION OF RISK}

\subsection{Runoff analysis using the tank model with observed real-time rainfall as input}

This study developed a simulation method that combines real-time rainfall observation and slope stability analysis. With rainfall $(\mathrm{mm})$ observed every minute as input, runoff analysis is performed using the tank model proposed by Ishihara and Kobatake (also used by the Japan Meteorological Agency for sediment disaster warning information) [7], and the amount of rainwater stored in the surface layer $S_{1}+S_{2}$ is calculated every minute. $S_{1}+S_{2}$ is rainwater $(\mathrm{mm})$ that actually permeates the surface layer, calculated by subtracting surface flow and outflow from the outermost layer from the precipitation. In the tank model, $\mathrm{S}_{1}+\mathrm{S}_{2}$ can be calculated as the storage capacity of the first and second tanks.

\subsection{Seepage analysis for groundwater generation and groundwater level determination}

When $S_{1}+S_{2}$ reaches a certain threshold, the high-water content zone proposed by Kawabata et al. [4] is assumed to have has reached base rock, and calculation of groundwater level generation begins. This threshold needs to be set according to the local slope's soil layer characteristics. In the study by Kawabata et al. [4], the volumetric water content ratio $\theta_{h}$ of the high-water content ratio zone formed under constant rainfall intensity was defined. Obtaining the volumetric water content ratio $\theta_{h}$ according to rainfall intensity $r$ that changes every minute is necessary. Therefore, we decided to obtain an approximate expression of the volumetric water content ratio $\theta_{h}^{\prime}$ that fits the experimental results of Kawabata et al. and to estimate the volumetric water content ratio by extrapolation even at rainfall intensity over $50 \mathrm{~mm} /$ hour.

$$
\theta_{h}^{\prime}=0.0388 \ln r+0.2064
$$

However, observations have clarified that rainfall intensity changes every minute, and the amount of change is great. Especially in short-time heavy-rain, the peak changes in a cycle of about 10 minutes, so in calculation of volumetric water content using the approximate eqn (1), we decided to use the average value of rainfall intensity for 10 minutes up to the current time. In addition, because the experiment by Kawabata et al. [4] was conducted on decomposed granite soil, it cannot be applied to soil with geotechnical properties significantly different from those of decomposed granite soil. 
When $\mathrm{S}_{1}+\mathrm{S}$ exceeds a certain threshold, the increased groundwater level due to rainwater that permeates the soil from the ground surface is calculated. Since the volumetric water content ratio corresponds to the pore space in the saturated state, it can be expressed by the following equation using the void ratio, $e$.

$$
\theta_{\text {sat }}=\frac{e}{1+e} \text {. }
$$

The difference between $\theta_{\text {sat }}$ and the volumetric water content ratio $\theta$ of the unsaturated soil in the high-water content zone before saturation, $\theta_{r}$, means the volumetric water content ratio at which rainwater permeating from the ground surface fills the unsaturated soil's voids.

$$
\theta_{r}=\theta_{\text {sat }}-\theta_{h}
$$

Therefore, the increase in groundwater level, $\Delta H(\mathrm{~m})$, due to rain water, $r(\mathrm{~mm})$ can be calculated by the following equation:

$$
\Delta H=\frac{r}{\theta_{r}} .
$$

In this study, however, determining soil parameters by a general soil test was important. Thus, the volumetric moisture content ratio, $\theta_{h}$ according to the rainfall intensity used in this analysis is estimated using eqn (5), obtained by experiments using materials differing from that of the local soil sample. Therefore, in this study, $\theta_{h}$ in eqn (7) is replaced with $\theta_{h}^{\prime}$ in eqn (5), and the amount of groundwater level rise is estimated by eqn (9):

$$
\Delta H=\frac{r}{\theta_{r}}=\frac{r}{\theta_{\text {sat }}-\theta_{h}^{\prime}} .
$$

After the groundwater level is generated, $r=S_{1}+S_{2}$ is the increment of groundwater supplied from the ground surface to the surface layer in 1 minute. In addition, calculating groundwater's inflow and outflow from the slope's adjacent surface blocks every minute is necessary [4].

The density of saturated soil $\rho_{\text {sat }}$ can be expressed using the density of water $\rho_{w}$ and the void ratio $e$ as follows:

$$
\rho_{\text {sat }}=\frac{G_{s}+e}{1+e} \rho_{w} .
$$

On the contrary, the density of unsaturated soil $\rho_{t}$ with a volumetric water content ratio $\theta_{h}$ can be given as follows:

$$
\rho_{t}=\frac{G_{s}+\theta_{h} e \rho_{w}}{1+e} .
$$

However, since $\theta_{h} \neq \theta_{h}^{\prime}$, the unsaturated soil's density $\rho_{t}$ is treated as a constant value as the soil's wet density as sampled in the field analysis. Slope stability analysis is performed in real-time based on fluctuating groundwater levels.

\section{REAL-TIME REPRESENTATION OF THE RISK OF SEDIMENT DISASTERS USING A CHART BASED ON THE GROUNDWATER LEVEL}

Slope stability analysis shows that when safety factor $F_{S}$ falls below 1 , the slope becomes unstable and collapses. Although engineers easily understand the safety factor, residents are not very familiar with it. Therefore, we thought that residents would find it difficult to use $F_{S}$ for evacuation decisions. Thus, the groundwater level when Fs becomes one is defined as the critical groundwater level $h_{w c}$, and $\alpha$, the ratio of the current groundwater level $h_{w}$ to the 
critical groundwater level, is used as an index indicating the degree of urgency of sediment disaster.

$$
\alpha=\frac{h_{w}}{h_{w c}} .
$$

Since 2020, evacuation information has been released in Japan by classifying alerts into five levels. Table 1 shows the relationship between alert level and evacuation information. Alert levels 1 and 2 are announced by the Japan Meteorological Agency as weather information, and warning levels 3 and above are issued by municipalities as evacuation information. Alert level 3 is for evacuation of the elderly, that is, the timing when elderly people and people with disabilities start evacuation with support; alert level 4 is the timing when healthy people start and complete evacuation; and alert level 5 calls for ensuring emergency safety where a disaster has already occurred. Among these, $\alpha$ in eqn (10) corresponds to alert level 4 , considered effective in communicating the degree of sediment disaster urgency as the groundwater level rises.

Fig. 2 shows this study's proposed chart. The green chart on the far left shows stages to alert level 2. The yellow chart shows the stage before the groundwater level is formed, but if rainfall continues, the groundwater level will be generated after approximately 1 to 2 hours. In this analysis, a threshold value is set for $\mathrm{S}_{1}+\mathrm{S}_{2}$, and when this threshold value is reached, the alert level is 3 , and a yellow chart is displayed. When $S_{1}+S_{2}$ further increases and reaches

Table 1: Alert levels and evacuation information.

\begin{tabular}{|c|c|c|c|}
\hline $\begin{array}{l}\text { Alert } \\
\text { level }\end{array}$ & Name of information & Required behavior & $\begin{array}{l}\text { Administrative } \\
\text { agency to issue }\end{array}$ \\
\hline 5 & $\begin{array}{l}\text { Ensuring emergency } \\
\text { safety }\end{array}$ & $\begin{array}{l}\text { Move to the upper floors or a safe } \\
\text { building }\end{array}$ & \multirow{4}{*}{ Municipality } \\
\hline \multicolumn{3}{|c|}{ Complete evacuation up to alert level 4} & \\
\hline 4 & Evacuation order & $\begin{array}{l}\text { Residents living in areas at high } \\
\text { risk of disaster begin to evacuate }\end{array}$ & \\
\hline 3 & $\begin{array}{l}\text { Evacuation of elderly } \\
\text { people, etc. }\end{array}$ & $\begin{array}{l}\text { Information to urge elderly people } \\
\text { to evacuate }\end{array}$ & \\
\hline 2 & $\begin{array}{l}\text { Heavy rain/flood/storm } \\
\text { surge warning }\end{array}$ & $\begin{array}{l}\text { Check evacuation behavior in } \\
\text { advance }\end{array}$ & \multirow{2}{*}{$\begin{array}{l}\text { Japan } \\
\text { Meteorological } \\
\text { Agency }\end{array}$} \\
\hline 1 & $\begin{array}{l}\text { Early warning } \\
\text { information }\end{array}$ & Early warning information & \\
\hline
\end{tabular}
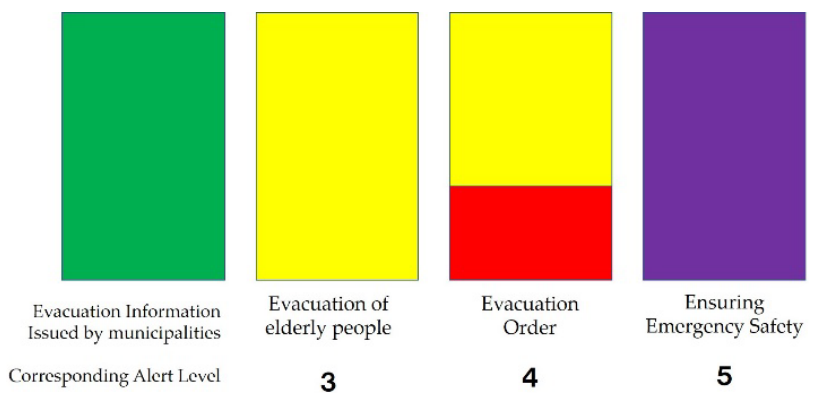

Figure 2: Charts to represent the state of slope stability corresponding to alert levels. 
the next threshold value, calculation of groundwater begins, and the chart turns to yellow and red with different ratios depending on the value of $\alpha$. That is, the red chart's height is shown as the ratio of the current groundwater level to the critical groundwater level. Finally, when the groundwater level reaches the critical groundwater level and the safety factor falls below 1 , the alert level changes to 5, and a purple chart on the far right in the figure is displayed.

\section{LOCAL APPLICATION}

\subsection{Overview of the target area}

The authors are conducting real rainfall observations in Nishikatsura Town, Yamanashi Prefecture, Japan. The Shimokurechi district of Nishikatsura Town is an alluvial fan located upstream of the Shakunagare River in the town's north-western part. The area has 330 households and a population of 900 . Almost all districts are designated as sediment disaster warning areas, and some are designated as sediment disaster special warning areas. Fig. 3, along with the Shimogurechi area's hazard map, shows the location of the rainfall observation point and of the slope that is this study's field.

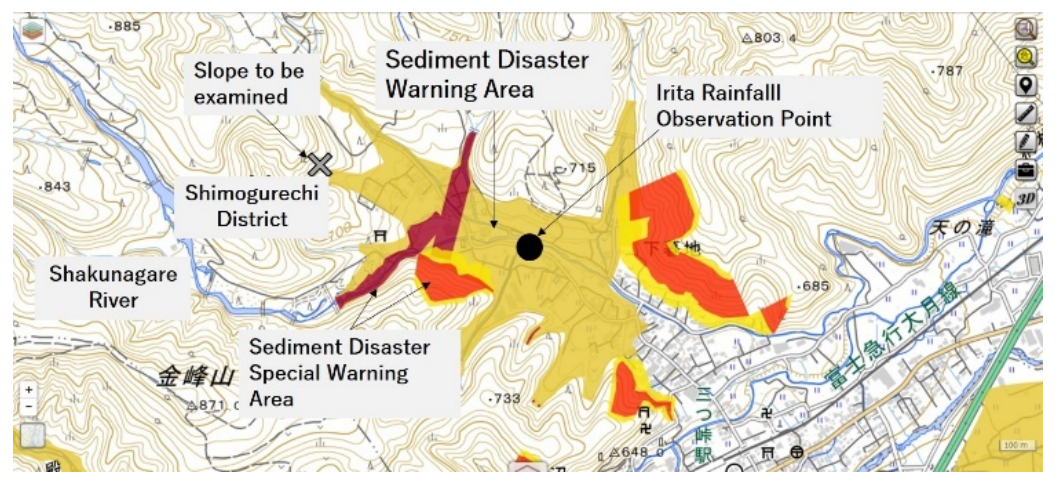

Figure 3: Locations of the rainfall observation point and the slope to be examined.

\subsection{Modelling the slopes based on a field survey}

Fig. 4(a) shows a photograph taken from the local slope of a residential area. This slope has had several slides, and after rainfall, its surface layer was muddy, with a lot of water, and rainwater flowed from the ground surface toward the residential area. A simple, standard penetration test was conducted along the slope of the valley to estimate surface thickness and slope angle of base rock. Results confirmed that the surface layer was almost uniform, of sandy soil, and with weathered conglomerate with an N-value of 1 to 2; Fig. 4(b) shows its profile. Using this cross section, seepage flow analysis was performed, and the slope safety factor was calculated for the No. 1 to No. 3 cross sections.

\subsection{Input parameters for surface layer}

Undisturbed soil samples were taken from the slope, and tests were conducted for density of soil particle, permeability, and direct shear resistance. Based on these results and the surface profile in Fig. 4(b), input parameters were summarized, as shown in Table 2. 


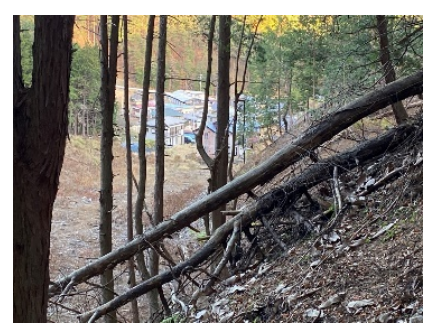

(a)

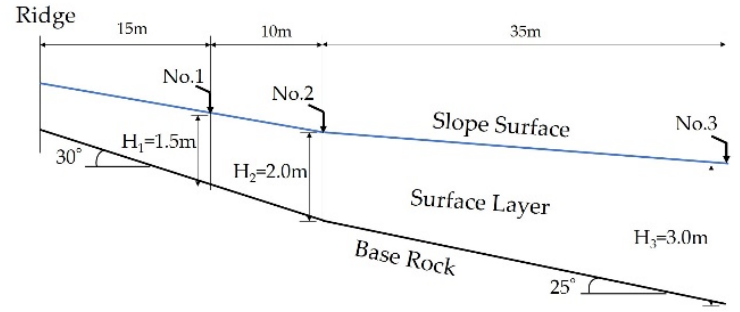

(b)

Figure 4: Local slope and residential area (sediment disaster warning area). (a) View of the residential area; and (b) Subsurface profile of the modelled local slope.

Table 2: Input data used in the simulation.

\begin{tabular}{|l|c|c|c|}
\hline & No. 1 & No. 2 & No. 3 \\
\hline Angle of slope, $\beta$ & 30.0 & 30.0 & 25.0 \\
\hline Thickness of surface layer, $H(\mathrm{~m})$ & 1.5 & 2.0 & 3.0 \\
\hline Density of soil particle, $\rho_{s}\left(\mathrm{~g} / \mathrm{cm}^{3}\right)$ & \multicolumn{3}{|c|}{2.585} \\
\hline Saturated density, $\rho_{\text {sat }}\left(\mathrm{g} / \mathrm{cm}^{3}\right)$ & \multicolumn{3}{|c|}{1.577} \\
\hline Wet density, $\rho_{t}\left(\mathrm{~g} / \mathrm{cm}^{3}\right)$ & \multicolumn{3}{|c|}{1.75} \\
\hline Void ratio, $e$ & \multicolumn{3}{|c|}{0.241} \\
\hline Volumetric moisture content ratio, $\theta$ & \multicolumn{3}{|c|}{036} \\
\hline Saturated volumetric moisture content ratio, $\theta_{\text {sat }}$ & $40.03^{\circ}$ \\
\hline Cohesion, $c\left(\mathrm{kN} / \mathrm{m}^{3}\right)$ & 3.80 & 3.84 & 3.84 \\
\hline Internal friction angle, $\varphi($ degree $)$ & \multicolumn{3}{|c|}{} \\
\hline Coefficient of permeability, $k(\mathrm{~m} / \mathrm{s}) \times 10^{-4}$ & \multicolumn{3}{|c|}{} \\
\hline
\end{tabular}

6 SETTING THE THRESHOLD OF $\mathrm{S}_{1}+\mathrm{S}_{2}$ FOR SIMULATION

To apply this simulation to the actual slope, indices must be established for alert levels 3 and 4 , respectively, to begin calculating groundwater level. Using the tank model, these indices were established according to the threshold value of the output value $S_{1}+S_{2}$ of the runoff analysis. Therefore, we conducted parametric studies in which $\mathrm{S}_{1}+\mathrm{S}_{2}$ was changed for the slope analysis model in the Shimogurechi district of Nishikatsura Town.

In 2019, Typhoon No. 19 brought heavy rainfall with accumulation of about $500 \mathrm{~mm}$ in Nishikatsura Town (Fig. 5), which issued an early evacuation advisory, based on rainfall information from the sediment disaster alert system developed by the author, to residents of sediment disaster warning areas, including the Shimogurechi district. According to a questionnaire survey conducted by Suzuki et al. [8], only 30\% of residents evacuated even within the area designated as a sediment disaster warning area, and voluntary evacuation was conducted in addition to issuance of evacuation advisories. Therefore, in addition to Nishikatsura Town's issuance of evacuation advisories, we decided to create new information - "an evacuation switch" - to encourage residents to evacuate voluntarily. Realtime rainfall observation was conducted at the Irita observation point at the confluence of small rivers, almost at the Shimogurechi district's center. Fortunately, no large debris flow occurred on the town's slopes, but violent surface flow was observed in the area's swamps, indicating a state just previous to a sediment disaster. 


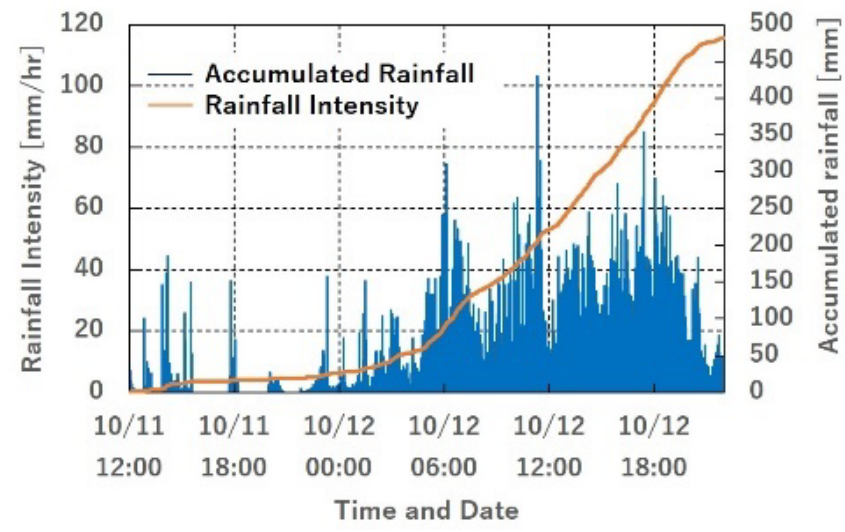

Figure 5: Rainfall observation record at Irita during Typhoon No. 19.

Fig. 6 shows results of the tank model's runoff analysis of observed rainfall data recorded every minute. The peak value of $\mathrm{S}_{1}+\mathrm{S}_{2}$ was about $210 \mathrm{~mm}$, and the soil-water index, which is a sum of $S_{1}+S_{2}$ and $S_{3}$, infiltration into the basement, was about $250 \mathrm{~mm}$ at the maximum. When $S_{1}+S_{2}$ reaches $140,150,160,170$, or $180 \mathrm{~mm}$, respectively, assuming that the highwater content ratio zone reaches the basement, the subsequent inflow of rainfall infiltration $\left(\mathrm{r}=\mathrm{S}_{1}+\mathrm{S}_{2}\right)$ and seepage along the slope's surface layer was analyzed. Then, according to the generated groundwater level, the slip safety factor was analyzed every minute. As a result of these parametric studies, Fig. 7 shows the time transition of the slip safety factor in cross sections No. 1 to No. 3. Results in which threshold values are 140,150, 160, 170, and $180 \mathrm{~mm}$, respectively, are compared in the figures.

For this rainfall event, the threshold value of $\mathrm{S}_{1}+\mathrm{S}_{2}$ was set so that the slope's slip safety factor was approximately 1 , that is, the verge of a sediment disaster. From these figures, in the case the threshold value of $S_{1}+S_{2}$ is $170 \mathrm{~mm}$, the safety factor is not less than one in the No. 1 and No. 3 cross sections, but is definitely less than one in No. 2. Therefore, we decided that the threshold value of $S_{1}+S_{2}$ for starting calculation of groundwater level was $170 \mathrm{~mm}$, so evaluation of alert level 4 was made at this stage. In contrast, the timing for displaying the alert level 3 chart was set to $130 \mathrm{~mm}$, about $75 \%$ of $170 \mathrm{~mm}$.

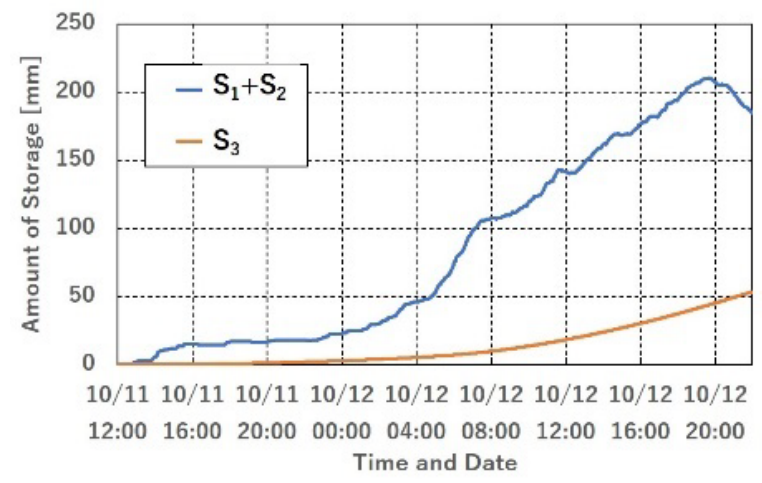

Figure 6: Results of runoff analysis by the tank model. 


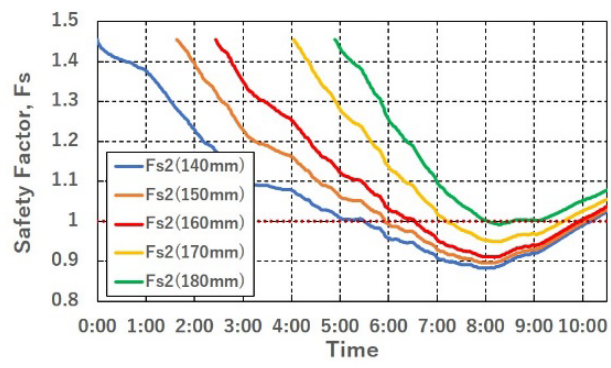

(a)

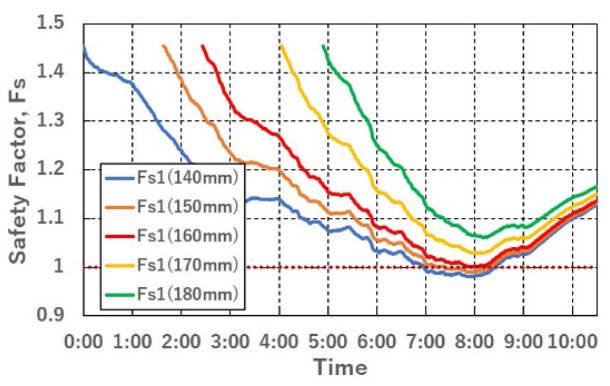

(b)

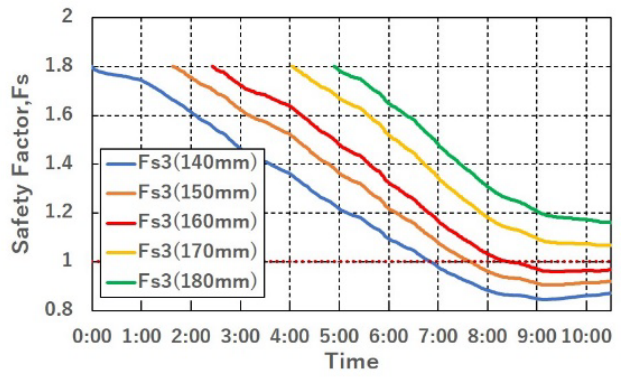

(c)

Figure 7: Time histories of the slip safety factor in the cross sections. (a) No. 1; (b) No. 2; and (c) No. 3

\section{DEVELOPMENT OF SEDIMENT DISASTER ALERT SYSTEM}

The authors are conducting real-time meteorological observations in Nishikatsura Town, Yamanashi Prefecture, Japan. An observation system that graphs the amount of rainfall observed every minute over a time span of 1 hour, 24 hours, and 72 hours is being used for disaster response. Furthermore, the sediment disaster risk web system that displays these on a map by color-coding rainfall intensity $(\mathrm{mm} / \mathrm{h})$ and dividing 72 -hour cumulative rainfall into six levels from 0 to 5 is used by Nishikatsura Town staff and fire brigade members during heavy rainfall.

Yamori calls the deciding level for evacuation of residents an "evacuation switch," a signal when a river's flooding reaches a certain level or water begins to accumulate in the lowlands [2]. However, in evacuation from debris flow disasters, groundwater level and soilwater content cannot be grasped without on-site observation, so it is difficult and dangerous for local residents to monitor a visual on-site evacuation switch. Therefore, in our sediment disaster alert system, a chart showing degree of urgency is displayed, so local residents can view it as an evacuation switch.

Fig. 8 shows the sediment disaster alert system's configuration. The proposed simulation is incorporated as a Fortran Module receiving rainfall data every minute in cooperation with a PHP application and analyzing the flag, groundwater level ratio, safety factor and so on that indicate the alert level. In addition, the groundwater level ratio is displayed on the sediment disaster alert system using an html application. Fig. 9 is a screen representation of this system.

The system was introduced by one of the authors at a gathering of Nishikatsura townspeople, to ward mayors and disaster prevention leaders who are participants in the 


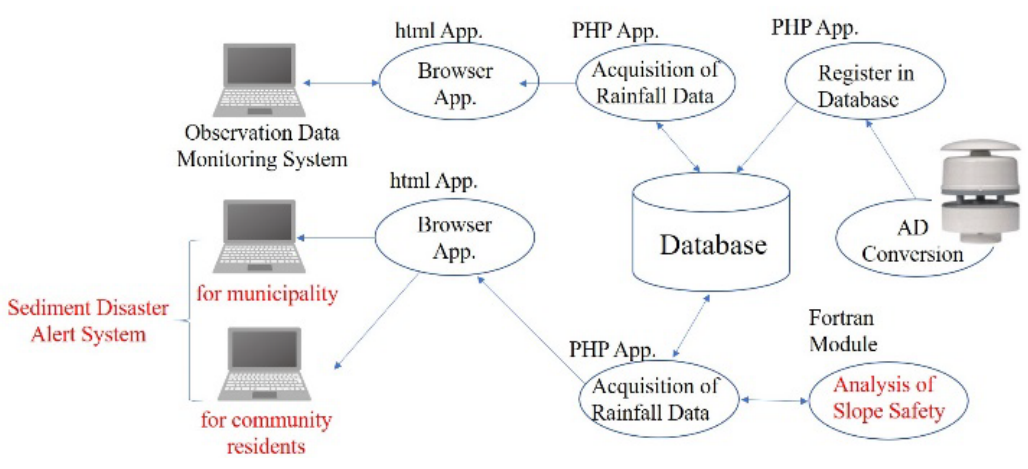

Figure 8: Configuration of the developed sediment disaster alert system.

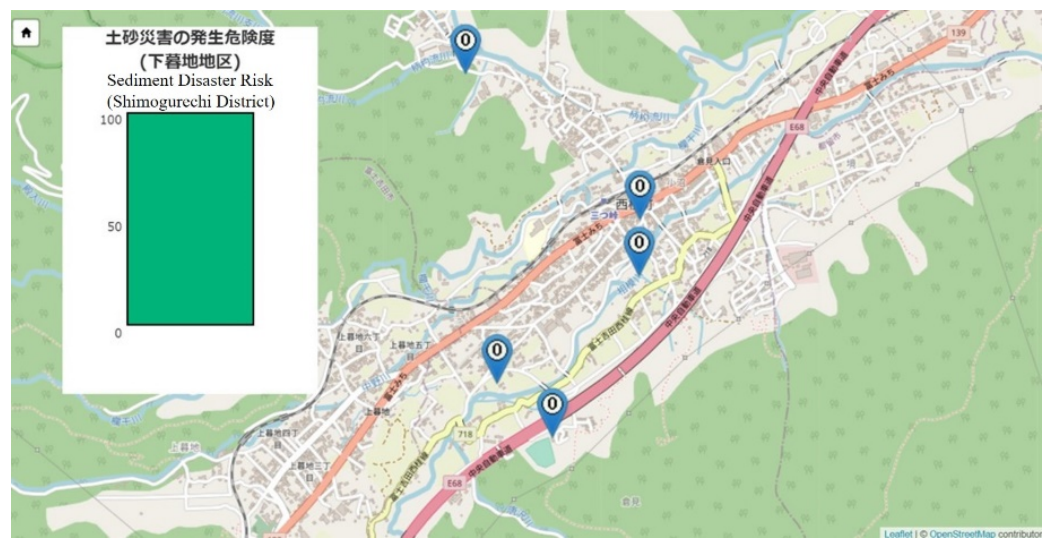

Figure 9: Sediment disaster alert system for residents.

gathering, and was evaluated as easy for residents to understand. In the future, we would like to add a supplementary explanation of the chart, so it will be even easier for residents to understand, and hold workshops with residents in the Shimogurechi district.

\section{CONCLUDING REMARKS}

For Nishikatsura Town, Yamanashi Prefecture, Japan, the authors developed a sediment disaster alert system with color-coded charts serving as an evacuation switch indicating sediment disasters' urgency. The system uses real-time rainfall observation as input data and performs real-time stability analysis based on a slope's rainwater runoff and infiltration simulations. A slope designated as a mountain stream from which debris is likely to flow was selected as the target. The simulation model was constructed based on-site exploration and soil testing results. For the sediment disaster alert system, a website was developed by combining the rainfall observation system and the simulation. To provide an evacuation switch for residents, the website expresses sediment disaster risk not by a safety factor but by a chart showing current groundwater compared to the groundwater level at which the slope becomes unstable and collapses. 
This system was constructed for the Shimogurechi area of Nishikatsura Town and has been experimentally operated as a switch for local residents' voluntary evacuation since the spring of 2021. We hope this system will be accepted by community residents, be operated in other districts of the town, and then be expanded to other municipalities.

\section{ACKNOWLEDGEMENTS}

The authors would like to express our gratitude to the General Incorporated Foundation Kyousou, Koden Electronics Co., Ltd., and the Yahoo! Fund for their research funding. The authors would like to thank Enago (www.enego.jp) for English language review.

\section{REFERENCES}

[1] Suzuki, T. \& Ito, T., Prediction of sediment disasters due to short-duration heavy rain based on real-time rainfall observation. WIT Transaction on The Built Environment, vol. 189, WIT Press: Southampton and Boston, pp. 91-99, 2019.

[2] Yamori, K., Missing of evacuation Information/FACP model/Evacuation switch: Rethinking evacuation from heavy rain disasters. Firefighting Science, 134, pp. 7-11, 2018. (In Japanese.)

[3] Montrasio, L., Valentino, R. \& Losi, G.L., Towards a real-time susceptibility assessment of rainfall-induced shallow landslides on a regional scale. Nat. Hazards Earth Syst. Sci., 11, pp. 1927-1947, 2011.

[4] Kawabata, S., Tsuchida, T., Kano, S., Yuri, A., Hanaoka, T. \& Nakagawa, S., Evaluation of the risk of sediment-related disasters during heavy rains in mountain streams based on ground surveys and slope stability analysis. Japanese Geotechnical Journal, 8(1), pp. 119-131, 2013. (In Japanese.)

[5] Yabe, M., Terada, Y., Nonami, K., Tobita, K., Ueno S. \& Sone, Y., Pore water pressure estimation method at the time of surface collapse using observation data and the tank model. Proc. Japan Society of Civil Engineers, C73(2), pp. 141-156, 2017. (In Japanese.)

[6] NEC, Sediment disaster sign detection system. https://jpn.nec.com/press/201708/ 20170830_01.html. Accessed on: 2 May 2021.

[7] Ishihara, Y. \& Kobatake, S., Runoff model for flood forecasting. Bulletin of the Disaster Prevention Research Institute, 29(1), pp. 27-43, 1979.

[8] Suzuki, T., Lyu, J. \& Ito T., Efforts for community disaster management to promote autonomous evacuation in sediment disasters: Efforts conducted at Shimogurechi district, Nishikatsuwra Town. Community Bosai, 21, 2021. (In Japanese.) 